\title{
24 ERP ADOPTION: SELLING THE SYSTEM
}

\author{
Dave Oliver \\ Faculty of Informatics and Communication \\ Central Queensland University \\ Rockhampton, Queensland \\ Australia \\ Lyn Oliver \\ Central Queensland Institute of TAFE \\ Rockhampton Campus, Queensland \\ Australia
}

\begin{abstract}
This paper presents a critical discourse analysis of an extract from an electronic newsletter, which was disseminated to staff by the vice-chancellor of a regional Australian university, announcing the adoption of an enterprise resource planning (ERP) system. The role of language as a strategic instrument in organizations is discussed. Themes relevant to issues of hegemony, agency, power, and ideology are identified. Contradictions are apparent, namely; the dichotomy between executive decision making and consensus generating, using change to define a stable state, and casting conforming to a software package as business process reengineering.
\end{abstract}

\section{INTRODUCTION}

It is known from Markus (1983) that political factors and resistance to change are important issues that need to be faced when new systems are introduced. Resistance to the use of new information systems is disruptive and may even lead to their abandonment, which implies an attendant waste of resources. From the perspective of custom development, Markus argues that resistance is a potentially constructive force that may be used to create more usable systems. However that is in a context where modification and adaptation

The original version of this chapter was revised: The copyright line was incorrect. This has been corrected. The Erratum to this chapter is available at DOI: 10.1007/978-0-387-35634-1_28 
are feasible. In enterprise resource planning (ERP) implementation, the systems have to be used where they are in the way they are; as Pozzebon (2000) puts it, the context is mandatory. Consequently, resistance may be viewed as an entirely negative force, which must be overcome, since the system cannot easily be changed. This requires management to exert extra effort to ensure acceptance of, and compliance with, the new systems.

This paper examines how the adoption of an ERP system is announced to the university in a message from the vice-chancellor in the weekly newsletter. This announcement is an initial step in attempting to overcome resistance to the new system. The newsletter is distributed electronically, and the vice-chancellor is a regular contributor; in fact, he writes a column every week on an issue that attracts his attention. The message is quoted in its entirety in the Appendix to this paper in order to enable readers to refer to the full context of those passages which are referred to in the subsequent analysis.

\section{ERP SYSTEMS}

Enterprise resource planning (ERP) systems have achieved considerable importance in the contemporary Information Systems arena. ERP systems are large and complex integrated software packages that support standard business activities. The scope of ERP systems, aligned with their numerous configuration alternatives and breadth of organizational impact, make the task of implementing them considerable, extending in many cases over several years. The extent to which ERP systems are shaping the IT industry are captured in the following comparison: "Twelve years ago, IT people identified their organizations as IBM or Digital shops, says Bruce Richardson, VP of Research at AMR Research Inc. They're now more likely to be SAP or PeopleSoft" (Sweat 1998). The financial impact is correspondingly significant: "By early 2000 the ERP revolution generated over $\$ 20$ billion in revenues annually for suppliers and an additional $\$ 20$ billion for consulting firms" (Willcocks and Sykes 2000). ERP systems have now been adopted by the majority of the Fortune 500 top firms and, as the high end of the market becomes saturated, ERP systems are filtering down to medium sized organizations such as universities, and to regions beyond those initially penetrated in Europe and North America (Kumar and Van Hillegersberg 2000). The widespread adoption of ERP systems, described as the "ERP revolution" (Ross 1999), presents the opportunity of investigating many aspects of this phenomenon, including the discourse surrounding how they are ushered in.

There has been a general advance and encroachment of information technology throughout universities for a very long time. Universities have become intensive users of IT in teaching, research, and administration. Although in 
adopting ERP systems it appears as if universities are mimicking the behavior of corporate bodies, as Fairclough (1993) observes, contemporary universities have adopted many of the behaviors that are associated with the commercial economy. In fact many of the activities that universities engage in are commercially orientated.

\section{LANGUAGE AS INSTRUMENT}

In the study of Information Systems, language has been a focus of interest primarily at the early stages of the system life cycle (for example Alvarez and Urla 2002; Auramaki et al. 1988; Urquhart 2000; Wynn and Novick 1995) and the database and artificial intelligence areas (Brooks and Belkin 1983;Paradis 1995; Riloff and Lehnert 1994). This paper focuses on the implementation phase of the system life cycle and examines one particular text, which is intended to justify the introduction of the new systems to the organizational audience. While this study is limited both to a specific context and text, the area it addresses, that of ERP system adoption, is of considerable importance and interest within Information Systems.

Language can be regarded as an important vehicle for the management of change within an organization. Management will wish to ensure that its decision to introduce new information systems is well received by those likely to be affected by them. The need to generate favorable attitudes and behaviors toward the new systems is a powerful motive for attempting to influence the organizational audience.

According to Robbins (1993), communication serves four major functions: to inform, to control, to motivate, and to express emotion. Management has the role of decision taker and will use language to inform workers that a change is forthcoming. In a medium-sized organization, such as a university, particularly where it is dispersed geographically, written communications are a convenient medium as they are not limited to time and place, and as Yates and Orlikowski (1992) observe, these days are likely to be electronically mediated.

Language is used in organizations to legitimate and control. The ability to communicate reflects the power relations that persist in an organization (Krippendorf 1980). A key issue is who is allowed to speak or write, about what, and when (Bergquist 1995). Power relations provide management with a position of discursive monopoly in organizations (Deetz 1992). Fairclough (1989) concludes, "We can say that producers [of text] exercise power over consumers in that they have sole producing rights and can therefore determine what is included and excluded." This is evident in the new forms of organizational communication based on the Internet where Web pages, newsletters, and other types of document intended for broad dissemination are produced and displayed 
under management control. According to Robbins, resistance to change can be reduced by education and communication. Language then becomes not simply a means of communication but a strategic tool that may be used to get people to adopt behaviors required by management (Habermas 1984).

We observe, in the context of ERP adoption, a rhetorical situation. Yates and Orlikowski refer to the definition of a rhetorical situation by Blitzer as an exigency, which in this context is an ERP system that needs to be implemented, an audience, the employees in the organization where the ERP system is to be deployed, and a constraint, those with the power to influence the situation, the managers. In this context, language becomes a vehicle for the exercise of power through the use of rhetoric to legitimate change. Willcocks and Smith (1995) point to this tactic of using rhetoric to attempt to develop attitudes and behaviors that will foster cooperation and commitment to process and IT changes.

\section{ANALYTICAL APPROACH}

This paper performs a critical discourse analysis of the vice-chancellor's message. The approach taken views discourse as a social practice. The statement is seen as instrumental action directed toward specific aims. The focus is not on the text as an embodiment of the abstract qualities of language as a set of grammatical rules but on the purpose of the text in its social context (Potter 1997). In discourse analysis, the focus is not solely on the use of words as linguistic objects, nor is the focus on the referential function of words, as it is in a number of qualitative research approaches. In discourse analysis, language is taken to be not simply a tool for description and a medium of communication (the conventional view), but as social practice, as a way of doing or achieving things. It is a central and constitutive feature of social life (Wood and Kroger 2000).

This analysis follows the approach to discourse analysis suggested by Fairclough (1989). The subsequent sections on The Corporate OutlookConsensus Generation, Agency Issues, and Vocabulary are strongly associated to his style of analysis. However, the sections on Change and Business Process Reengineering Paradoxes are inspired more by the Information Systems context itself. The aim is to go beyond content to see how it is used to achieve particular functions and effects. As Fairclough (1989) has shown, language may be analyzed to examine underlying issues of power and ideology. This emphasis on discourse as action entails a shift from the usual focus of interest in the phenomena to which the discourse refers, to a focus on the discourse itself (Wood and Kroger 2000). Also after Fairclough (1989, 1993), relational issues involving how the text appears to the reader and its place within wider social dimensions assume greater importance. The text does not exist in isolation. It is 
essential to understand the context in which the text is produced, both institutional and social.

\subsection{The Corporate Outlook-Consensus Generation}

A difficulty faced by senior managers introducing change in an organizational context is the apparent need to reconcile the contrasting requirements of executive decision making with the broad consensus required to successfully implement decisions. As Axley (2000) observes,

We live in a time when neither "Because I said so..." nor simple positional authority carry the kind of motivating weight they used to among organizational members. Today's employees often must see for themselves the merits of a change before they will be compliant, let alone committed to a change.

A theme evident in the first paragraph of the passage is the attempt by the vicechancellor to generate an inclusive atmosphere. This may be contrasted to a more imperative use of language as in a directive. This is evident in the frequent use of the pronouns we and our to create a corporate view of the context of change. In describing the student system, however, it is "our student system" causing "our grief." This is not so much the corporate body our as it is the more intimate you and I (unfortunate) users of this administrative system. There is a sense in which the reader is invited to recall or relive their personal experiences of grief caused by using the system. There is a great effort to generate a climate of inclusiveness in the third sentence of this first paragraph. It uses the corporate we no less than six times in contrasting various institutional changes since 1976!

In the second paragraph, the term "our Council" - that is, the governing body of the university - expresses an inverse ownership relation. Normally references are simply to Council as in the next paragraph (need for Council approval, no our); in other words, a fairly distant and impersonal relationship is maintained in language, for what is after all a rather remote group who exercise nominal control over all of the university, who give final approval of decisions handed to it, who do not intervene in day to day affairs, and who do not as a rule generate issues of their own. In this account there is a suggestion of possession or ownership by employees over council, which does not relate to the conventional view. The use of our here appears to be used to foster the idea of a kind of paternalistic our, a group who evidently has the best interests of the university at heart. This helps to give the impression that the decision to adopt ERP is collective and to everybody's benefit. 
In addressing the introduction of the new systems, the writer maintains the use of a corporate perspective. The writer asks the rhetorical question of "is it now just a matter of loading some new software, sitting back, and watching all our problems disappear before our eyes?" (emphasis added). Here we see the use of "our problems" disappearing before our eyes. "We are looking at more than two years of very intensive work, in which we must essentially review every significant business process of the university" (emphasis added) creates an agenda of collective effort. The ERP system is not an instant cure for the previously mentioned difficulties; it is going to require a considerable amount of work to realize the envisaged gains. One of the paradoxes of ERP systems is that, although they are off-the-shelf software packages, installing them and adapting to them remains a long and complex task.

At the beginning of the passage, a feeling of intimacy and shared concerns is created by the use of the first person singular in the vice-chancellor's identification with emotions resulting in "cries of despair." Similarly, he aligns himself with the staff of the university in the term "our grief." However, in juxtaposition to this perspective, the vice-chancellor attempts to engage the employees in the ownership of the very university systems that are the cause of their frustration. Instead of referring to these systems in the third person, he employs the first person plural to indicate possession. Paragraph seven also uses the corporate we, again affirming ownership.

A relational shift occurs in paragraph four where a more distant connection between the institution and its employees is expressed. In that paragraph, it is a case of $u s$ reviewing the processes and transactions of the organization, thus creating a detachment between the organization and the people working for it. This detachment is also shown in the first sentence of paragraph eight, where the corporate we and our are eschewed in favor of the implementation of the system requiring commitment and training. So we find different relations at different times placed between the reader and the corporate body. If the focus is on togetherness the we is you and I. Alternatively, we may be the corporate body of which the reader is a part and again on other occasions the corporate body is presented as separate and distinct.

Similarly "implementation will require ownership" neglects to explain how this ownership will be granted. In what sense is ownership possible in this context? Can employees be made to own something they made no effort to acquire and may not even want? Ownership is evidently perceived to be important. Ownership, like empowerment, is a currently fashionable concept, and implies commitment, which from a managerial point of view is desirable. Apart from the communication tactic to generate buy-in suggested by the vicechancellor, how else can commitment be generated? 
A conflict between hegemony and cooperation is evident in this situation. A decision has been made by those who manage the organization; yet for this decision to succeed, the approval of a large number of people who were not a party to the decision must be gained. Also there is a tension between the needs of organization as a detached entity and those of individual people who comprise the organization. This is evident from the equivocal references to the organization as an it on some occasions with needs of its own and on others as an entity belonging to employees, in the use of we and our, suggesting that the organizational needs and employees are identical.

\subsection{Agency Issues}

The authority for implementing the system is not presented as coming from the vice-chancellor or other responsible agency within the university. It is "our Council" who have accepted a recommendation. Who actually put forward this major proposal is not divulged. Hence there is an avoidance of attributing the decision to anybody identifiable with the daily operation of the university. This avoidance of responsibility may be a type of defense mechanism adopted by senior people in bureaucratic organizations in case a project turns out to be unsuccessful. Blame for a poor decision then becomes difficult to attribute. Alternatively it may be a way of diluting the expression of power inherent in the ERP exercise by pretending that the recommendation to purchase simply emerged spontaneously, on its own.

There are positive gains, readers are told in paragraph four, from adopting the new system. There is a pay-off in terms of savings; however, these are not quantified. Nevertheless the reader is given the impression that the activity is beneficial and that gains will occur to the university. The reader learns that the savings are to be partially achieved by efficiency reviews of business processes. A further use of the collective we informs the reader that these reviews of existing processes should in any case be occurring, but the issue of who should be instigating the reviews is not made apparent. No responsibility or agency for efficiency improvements is identified, other than the introduction of the new system. In this sense, the ERP system provides a pretext for efficiency reviews, which may well be overdue, but would probably never happen without this or some other powerful stimulus.

\subsection{Vocabulary}

The description of a communication strategy to be employed in paragraph eight "to ensure universal understanding and buy-in" is interesting for a number 
of reasons. A communication strategy suggests the use of language for the specific purpose of gaining acceptance of the new system, i.e., using language for a strategic purpose as was suggested at the beginning of the paper. Here communication is acknowledged as of strategic value. Indeed the very article is itself part of the communication strategy it is referring to, so in this sense the text is reflexive. Precisely who is developing the communication strategy is not clear. Also it seems a little incongruous to suggest to the very people to whom this strategy is directed that they are going to be the recipients of a sales campaign to gain their compliance and acceptance.

The title of this message, systematic changes, introduces a note of regularity into what is perceived by many in the university to be a fairly dramatic event, namely the expenditure of a large sum of money, about $\$ 14$ million Australian dollars, on an IT project (the figure of $\$ 14$ million emerged later; in this passage, the cost is simply referred to as high). The choice of title indicates the writer has an exceptionally broad command of the English language. The changes proposed are changes to the information systems of the university, hence they are systematic, in the sense that they are "of the system"; however, this is an unusual context in which to apply the word. Usually the word systematic is taken to mean methodical or regular, but changes to university information systems are exceedingly infrequent occurrences and hence not regular. There is a play on words here, as is often the case with titles.

The student system is described as causing cries of despair and grief. The interface between the student system and the finance system is the cause of "many nightmares." Because nightmares emerge in sleep when there is no conscious control over mental processes, images of alarm and powerlessness are evoked. A person will want to shake off a nightmarish situation and if possible eliminate the cause to prevent repetition. These powerful images are used to justify the replacement of the existing discrete student and finance systems with one integrated system. Perhaps the reader will be encouraged to believe that it is necessary to go to any lengths to replace them. The imagery is intensified by the prospect of nightmares getting worse with the risk of total collapse. This scenario is likely to create concern on the part of the readership and serves as a further justification for the replacement of the existing systems. We have a vocabulary of anguish and impending danger to set the scene for the introduction of the ERP system as an avenue of escape.

The implementation timetable will be aggressive (paragraph eight). This use of terminology associated with battle is indicative of the emotional charge underlying the exercise of ERP adoption. The organization is a battlefield on which the advance of the new system will be mapped. Its speed of advance will depend on the aggression shown by its initiators. The idea of competitive advantage with other institutions advanced in paragraph nine pursues this idea of battle for supremacy. 


\subsection{Change}

The writer creates a climate of change by giving examples in which both the institution and the world of technology has changed over the last quarter century. These references to change help to legitimate the change that is now being heralded. The accumulation of adverbial clauses commencing with "When we..." in the opening paragraph (six in fact) serves to emphasize change as the agency of the present exigency. The repetitions also emphasize the distance in time since the systems were installed. Changes that have occurred in the past are used to define a stable state which the ERP system is able to serve. This is used to justify changing the information system. Paradoxically, changing the information system in the case of changing to ERP necessitates the institution changing to suit the system, not the system to the changed needs of the institution.

Past changes are presented as the essence of the university as it currently exists. It is presented that these changed attributes now constitute university life. However, casting these changes as concrete serves to ignore the essential aspect of change, namely that it is ongoing and cannot by definition present a stable basis upon which to build. Determining to use an ERP system because it meets current requirements does not provide any guarantee that it will be adaptive toward future changes that the university may face. The nature of change is that it produces future outcomes which are unpredictable.

\subsection{Business Process Reengineering Paradoxes}

Paragraph five adopts the rhetoric of business process reengineering, where the best processes are those that no longer exist. This type of drastic reductionism is most strongly associated with Hammer (1990), the title of whose article, "Reengineering Work: Don't Automate, Obliterate," makes plain the advocacy of discarding old processes. The examples of removing processes are taken from the academic agenda of the university, which the vice-chancellor as an academic himself is probably most comfortable discussing, compared to business processes of a more administrative flavor. However, these examples reveal another paradox in ERP adoption. Subject prerequisites were not handled by the former student system, however they are by the ERP system. Consequently this represents an addition to work rather than removal of work, since the prerequisites will need to be more carefully managed in the new system.

Reviewing processes in the context of ERP adoption, however, means conforming them to the system. Processes will certainly be changed, but they will not necessarily become cheaper and more efficient, although the ideology of business process engineering implies this will be the case. Paragraph seven 
enshrines this hope; however, as is revealed elsewhere, it is not the efficiency of processes that is the issue, it is whether or not they are supported by the system. Although it is alleged that it is an efficiency goal rather than a technology goal that is being pursued, the only changes that will occur are those driven by the new system.

The real consequences of ERP adoption are revealed in paragraph four. The agenda shifts here, not from reviewing processes to create efficiencies but to conform processes to the ERP system. It is clear that the duty of the corporate body is to conform to the new system ("We must conform..."). This need to conform is stated in very strong terms. A change that requires a deviation from the system will only be sanctioned by the ultimate power source within the organization: the vice-chancellor himself.

We learn that a high status university (the University of New South Wales) is doing the same thing. It is always comforting, when implementing new systems, to follow in the footsteps of someone else, especially if they have a high reputation. However, a lengthier interval would have enabled a more considered view of the leader's experience, should that have been sought. Conformity to the ERP package is euphemistically described as reform. Reform is an altogether more satisfactory term to use from the point of view of casting ERP adoption as a positive step for the university. In light of a subsequent Academic Board meeting at the university where a similar passage of reform was presented, the nature of the reform could better be described as a process of "re-terminology." The extensive change in nomenclature (for example, program instead of degree) reflects a process of cultural domination rather than reform.

\section{DISCUSSION}

The widespread acceptance of ERP systems is significant to the Information Systems community. The analysis of this discourse sheds further light on the phenomenon. From the disparaging remarks made about the student system and its poor interface to the finance system, we can discern that dissatisfaction with existing systems may have been of some effect in prompting ERP adoption. It emerges as a justification or rationale. Dissatisfaction is regarded as a significant motivation for ERP adoption by Boudreau and Robey (1999). Similarly the reference to other universities adopting this system suggests that imitation may have been of some influence and also serves the purpose of legitimating the activity (DiMaggio and Powell 1983; Oliver 1991). The rhetoric of business process reengineering provides further justification. As Bancroft et al. (1997) note, business process reengineering is, as it appears in this example, difficult to differentiate as a separate activity from ERP itself: "Many companies are attracted to ERP because it implies fundamental organizational changes. Indeed, 
ERP usually instigates, or is instigated by, business process reengineering." Although business process reengineering has its own logic and rationale, it appears to offer a convenient euphemism for conforming processes to those of an ERP system. Information systems professionals should consider the question of whether the occasion of new systems being implemented is an appropriate time for reviewing existing processes with a view to eliminating them. From this instance it would seem that for some organizations this is likely to be the only time when such issues are addressed.

Today the IS worker is more likely to be a system implementer than a developer, facilitating the introduction of new packaged systems. The assumptions and ideologies that are implicit in this type of workplace reorganization deserve the closest attention. The IS professional needs to be a discriminator of potential new systems and be aware of the bases upon which they may be justified to users. From this, new opportunities should emerge for IS professionals as systems implementers in the wake of announcements similar to the one analyzed in this paper, and also as effective requirements analysts and evaluators of new systems.

\section{CONCLUSION}

It is difficult to form firm conclusions or recommendations from this paper. A single discursive event does not provide a sufficient basis from which to do this. Also a critical approach does not present new ideas or lend itself to theory formation, but rather aims to provoke reflection. However this paper does provide an opportunity for IS professionals, who may be immersed in systems development and other technical activities, to examine management perceptions of how workers should identify with the introduction of new information systems. ERP systems are at the forefront of new systems implementation in many organizations. They are indicative of the extent to which information systems have become a commodity to be installed within organizations at management's behest. It is, therefore, important to realize how these systems are represented to the organizations in which they are placed.

To ensure staff acceptance and compliance, there is a need for management to sell new packaged systems to the organization. Whereas custom systems emerge after a long development process occurring within the organization and therefore have the opportunity to find gradual acceptance, the adoption of a packaged solution has a more immediate and profound impact, in spite of the lengthy implementation phase. It is clear that communication can play a strong supporting role in generating ownership of the new system. This particular text uses strongly emotive language to dismiss the old systems but does not elaborate on the specific deficiencies of these old systems or ways in which the new 
system will be superior, apart from being integrated and newer. Problems with the old systems are presented as shared frustrations. Acceptance of new systems requires first that the old systems be denigrated, and this has more impact if readers can be prompted to recall their own bad experiences with the old system.

The emphasis on the development of a corporate view toward the adoption of the ERP system in this passage is distinctive. The aim is to develop a sense of commitment and ownership of the new systems. It is "our Council" that has approved the replacement, suggesting a sharing of responsibility for the new state of affairs. This shows an effort is made to make the new systems appear to belong to everybody. Also, the considerable implementation task requires a committed and motivated workforce that will be willing to adapt to the requirements enforced by the new system. A need to develop a team spirit is evident.

Yet from another perspective, it is apparent that a detached attitude to the organization needs to be generated. This is because the organization's processes need to be viewed objectively rather than from a sense of ownership if the dictates of the new system require that positions and processes be abandoned or radically revised. Also, the agency responsible for bringing about changes may similarly be presented as detached in this passage, to avoid the implication that the new system is being imposed.

A variety of anomalies in institutional life are revealed in this text. Systems that have served the organization for a long time need to be denigrated to usher in the new, as yet untried and untested systems. Hegemony dictates decisions are made at the top, successful outcomes require that decisions be accepted throughout. Ownership suggests collective responsibility and decision making; hegemony imposes decisions and yet interestingly evades issues of responsibility. Agency is muted. Change is depicted as defining a state; in practice it is ongoing. Business process reengineering proclaims efficiency; installing an ERP system necessitates conforming.

From this discourse analysis, the importance of communication between management and workers both before and during initiation of a new information system can be appreciated. Staff need to be made aware of the limitations of the old system and encouraged to perceive the advantages inherent in the new. This period of transition can then be valued positively and feelings of personal and institutional ownership engendered.

\section{REFERENCES}

Alvarez, R., and Urla, J. "Tell Me a Good Story: Using Narrative Analysis to Examine Information Requirements Interviews during an ERP Implementation," The DATA BASE for Advances in Information Systems (33:1), 2002. 
Auramaki, E., Lehtinen, E., and Lyytinen, K. "A Speech-Act-Based Office Modeling Approach," ACM Transactions on Office Information Systems (6:2), 1988.

Axley, S. R. "Communicating Change: Questions to Consider," Industrial Management, 2000.

Bancroft, N. H., Seip., H., and Sprengel, A. Implementing SAP R/3: How to Introduce a Large System into a Large Organization, Second Edition. Upper Saddle River, NJ: Prentice-Hall, 1997.

Bergquist, W. H. The Postmodern Organization: Mastering the Art of Irreversible Change. San Francisco: Jossey-Bass, 1995.

Boudreau, M., and Robey, D. "Organizational Transition to Enterprise Resource Planning Systems: Theoretical Choices for Process Research," in P. De and J. I. DeGross (eds.), Proceedings of the International Twentieth Conference on Information Systems, Charlotte, North Carolina, 1999.

Brooks, H. M., and Belkin, N. J. "Using Discourse Analysis for the Design of Information Retrieval Interaction Mechanisms," in Proceedings of the Sixth Annual International ACM SIGIR Conference on Research and Development in Information Retrieval. New York: ACM Press, 1983.

Deetz, S. "Disciplinary Power in the Modern Corporation," in M. Alvesson and H. Willmott (eds.), Critical Management Studies. London: Sage, 1992.

DiMaggio, P. J., and Powell, W. W. "The Iron Cage Revisited: Institutional Isomorphism and Collective Rationality in Organizational Fields," American Sociological Review (48), 1983, pp. 147-160.

Fairclough, N. Language and Power. Harlow, UK: Longman Group, 1989.

Fairclough, N. "Critical Discourse Analysis and the Marketization of Public Discourse: The Universities," Discourse \& Society (4:2), 1993, pp. 133-168.

Habermas, J. The Theory of Communicative Action and The Rationalization of Society. Boston: Beacon Press, 1984.

Hammer, M. "Reengineering Work: Don't Automate, Obliterate," Harvard Business Review, July-August 1990, pp. 104-112.

Krippendorf, K. Content Analysis. London: Sage, 1980.

Kumar, K., and Van Hillegersberg, J. "ERP Experiences and Evolution," Communications of the $A C M,(43: 4), 2000$.

Markus, M. L. "Power, Politics, and MIS Implementation," Communications of the ACM (26:6), 1983, pp. 430-444.

Oliver, C. "Strategic Responses to Institutional Processes," Academy of Management Review (16:1), 1991, pp. 145-179.

Paradis, F. "Using Linguistic and Discourse Structures to Derive Topics," in Proceedings of the Fourth International Conference on Information and Knowledge Management (CIKM'95), 1995.

Potter, J. "Discourse Analysis as a Way of Analyzing Naturally Occurring Talk," in D. Silverman (ed.), Qualitative Research: Theory, Method and Practice. London: Sage, 1997, pp. 144160.

Pozzebon, M. "Combining a Structuration Approach with a Behavioral-Based Model to Investigate ERP Usage," in H. M. Chung (ed.), Proceeding of the Sixth Americas Conference on Information Systems, Long Beach, CA, 2000.

Riloff, E., and Lehnert, W. "Information Extraction as a Basis for High-Precision Text Classification," ACM Transactions on Information Systems (12:3), 1994.

Robbins, S. P. Organizational Behavior: Concepts, Controversies, and Applications. Upper Saddle River, NJ: Prentice Hall, 1993.

Ross, J. W. "The ERP Revolution: Surviving Versus Thriving," Working Paper, Sloan School of Management, Center for Information Systems Research, Massachusetts Institute of Technology, 1999. 
Sweat, J. "ERP: The Corporate Ecosystem," Information Week Online, 1998.

Urquhart, C. "Analysts and Clients in Conversation," in W. J. Orlikowski, S. Ang, P. Weill, H.

C. Krcmar, and J. I. DeGross (eds.), Proceedings of the Twentieth-First International Conference on Information Systems, Brisbane, Australia, 2000.

Willcocks, L., and Smith, G. "IT-Enabled Business Process Reengineering: Organizational and Human Resource Dimensions," Journal of Strategic Information Systems (4:3), 1995, pp. 279-301.

Willcocks, L. P., and Sykes, R. “The Role of The CIO and IT Function in ERP," Communications of the $A C M(43: 4), 2000$.

Wood, L. A., and Kroger, R. O. Doing Discourse Analysis: Methods for Studying Action in Talk and Text. Thousand Oaks, CA: Sage Publications, 2000.

Wynn, E., and Novick, D. "Conversational Conventions and Participation in Cross-Functional Design Teams," in D. G. Novick (ed.), Proceedings of the Conference on Organizational Computing Systems (COOCS'95), 1995.

Yates, J., and Orlikowski, W. "Genres of Organizational Communication," Academy of Management Review, April 1992.

\section{About the Authors}

Dave Oliver is a Senior Lecturer in Computing at Central Queensland University, Australia. He has an honours degree in Economics from Warwick University, UK, and a Master of Technology degree in Computer Science from Brunel University, UK. Dave has published papers in the SIGCSE journal of the $\mathrm{ACM}$ and has presented papers at a number of international conferences. He has been the course coordinator for a number of degree courses in Computing at Central Queensland University. Prior to his lecturing appointment at Central Queensland University, Dave lectured at the Harrow College of Higher Education in the UK and worked as a computer programmer in the City of London. He can be reached by e-mail at d.oliver@cqu.edu.au

Lyn Oliver is currently a course coordinator in the language and literacy area of The Adult Learning Centre at Central Queensland Institute of TAFE, Australia. Previous employment includes working and lecturing in IT in the UK and teaching at all levels from primary to tertiary in communication subjects in England and Australia. Qualifications include BA Hons in English and American Literature, a Graduate Certificate in Education and Vocational and Training qualifications in Adult Literacy, Disability and Workplace Training. Lyn can be reached by e-mail at Marilyn.Oliver@det.qld.gov.au. 


\section{APPENDIX}

\section{CQU UniNews \#266 (10/6/1999) FROM THE VICE-CHANCELLOR'S DESK: SYSTEMATIC CHANGES}

[1] I have probably heard, and indeed contributed to, more cries of despair in relation to the quality of our systems than to any other single matter. Our student system in particular has been blamed for much of our grief. This is perhaps hardly surprising when one remembers it was purchased, second hand, in 1976, when we were not a university, when we only had two semesters, when we only had one campus, when we had no honors or research students, when we had no full fee-paying students, when we had no HECS-liable students, and nobody in Australia had a personal computer. All these things have changed and today our operation is essentially characterized by these changes.

[2] At its meeting this week, our Council accepted a recommendation that we proceed to implement, in conjunction with Andersen Consulting, the PeopleSoft integrated student, finance, and human resource system. The poor interface between our current student system and our current finance system is the source of many nightmares. These will get worse if the Federal Government moves to allow universities to set their own fees for publicly supported students, and permits price competition between universities.

[3] The costs of replacing our systems are high; hence the need for Council approval. The costs of not doing this include a real and unacceptably high risk of total collapse, notwithstanding that our current student and finance systems are $2 \mathrm{~K}$ compliant.

[4] So, is it now just a matter of loading some new software, sitting back, and watching all our problems disappear before our eyes? Not a bit of it. We are looking at more than two years of very intensive work, in which we must essentially review every significant business process of the university. Many of the savings that are part of the pay-off of new systems arise because their imminent arrival disciplines us to review the processes and transactions through which the organization conducts its internal and external business. (These are reviews we should be conducting in any case.) We must conform our processes to the systems we are purchasing, and not the other way round. For every change we make to the systems we significantly both delay the introduction and inflate the price of upgrades, add-ons, and new versions of the software. Therefore our aim must be to secure an absolute minimum of changes. For that reason no change will be permitted without the approval of the Vice-Chancellor, and that approval would only be given in the most compelling of circumstances. The argument that unless the system is changed we will not be able to go on 
managing ourselves or conducting business in the ways we have done in the past will not be accepted as compelling.

[5] This also provides us with an opportunity to ask, of every transaction and process type we conduct, is it really necessary to do this at all? To the extent that we can take transactions and processes out of the organization, to that extent we reduce our operating costs. For example, do we really need to keep a system of subject prerequisites, which still operates in a large number of our award courses? The human labor costs, as well as the complications to any system we use, of verifying compliance, and managing discretion in prerequisite waiver, are costs that add no obvious value to the quality of our work. Many universities have now scrapped formal prerequisites altogether, in favor of an advisory "assumed knowledge". Equally, we are now beginning to realize that "show cause" procedures really contribute nothing of value to quality control, and are a throwback to the long gone days when access to university places was much more heavily rationed.

[6] In making the decision to adopt and implement PeopleSoft, we are fortunate in having the benefit of the experience of the University of NSW, about nine months ahead of us, which is introducing the same integrated system with the same implementation partner. They have remarked on the unprecedented amount of reform that has passed through their Academic Board, along the lines just indicated, under the discipline of the implementation of PeopleSoft.

[7] I cannot stress often enough that what we are implementing is not a new IT system, or simply a new and highly sophisticated software package. We are looking at reforming the ways we conduct every significant aspect of our internal and external business, to ensure that all our transaction and process types add value to the quality of our work to a level at least commensurate with their cost.

[8] The implementation and operation of the new integrated system will require commitment and training right throughout the organization. We are setting considerable sums of money aside to provide that training so no section of the University will be inhibited in extracting full value from the changes. Implementation will require ownership at all levels and from all sections of the University. A communication strategy is being developed as a high priority in a major effort to ensure universal understanding and buy-in. Our timetable for implementation will be aggressive, though probably less so than that at UNSW. Although we have a similar academic structure with Faculties based on multidisciplinary Schools, we have more campuses and a greater variety of modes of study than UNSW.

[9] Universities already committed to a major involvement with PeopleSoft - though not all in precisely the same areas as CQU and UNSW - include USQ, 
ANU, Griffith, Sydney, and UQ. We are in a very strong position to secure competitive advantage from our implementation, in that we are far enough behind the lead site, UNSW, to benefit from its experience, and far enough ahead of most of the others to be early beneficiaries of the efficiency dividends. And that's not a bad position to be in.

Professor Lauchlan Chipman Vice-Chancellor and President

[Note: Paragraph numbers added for ease of reference.] 